University of Nebraska - Lincoln

DigitalCommons@University of Nebraska - Lincoln

Faculty Publications: Department of

Entomology

Entomology, Department of

2007

\title{
Physiological and Biochemical Responses of Resistant and Susceptible Wheat to Injury by Russian Wheat Aphid
}

\author{
Lisa D. Franzen \\ University of Nebraska-Lincoln \\ Andrea R. Gutsche \\ University of Nebraska-Lincoln \\ Tiffany Heng-Moss \\ University of Nebraska-Lincoln, thengmoss2@unl.edu \\ Leon G. Higley \\ University of Nebraska-Lincoln, Ihigley1@unl.edu \\ Gautam Sarath \\ USDA-ARS, University of Nebraska-Lincoln, Gautam.sarath@ars.usda.gov \\ See next page for additional authors
}

Follow this and additional works at: https://digitalcommons.unl.edu/entomologyfacpub

Part of the Entomology Commons

Franzen, Lisa D.; Gutsche, Andrea R.; Heng-Moss, Tiffany; Higley, Leon G.; Sarath, Gautam; and Burd, John D., "Physiological and Biochemical Responses of Resistant and Susceptible Wheat to Injury by Russian Wheat Aphid" (2007). Faculty Publications: Department of Entomology. 275.

https://digitalcommons.unl.edu/entomologyfacpub/275

This Article is brought to you for free and open access by the Entomology, Department of at DigitalCommons@University of Nebraska - Lincoln. It has been accepted for inclusion in Faculty Publications: Department of Entomology by an authorized administrator of DigitalCommons@University of Nebraska - Lincoln. 


\section{Authors}

Lisa D. Franzen, Andrea R. Gutsche, Tiffany Heng-Moss, Leon G. Higley, Gautam Sarath, and John D. Burd 


\title{
Physiological and Biochemical Responses of Resistant and Susceptible Wheat to Injury by Russian Wheat Aphid
}

\author{
LISA D. FRANZEN,${ }^{1}$ ANDREA R. GUTSCHE ${ }^{1}$ TIFFANY M. HENG-MOSS,${ }^{1,2}$ LEON G. HIGLEY, ${ }^{1}$ \\ GAUTAM SARATH, ${ }^{3}$ AND JOHN D. BURD ${ }^{4}$
}

\begin{abstract}
J. Econ. Entomol. 100(5): 1692-1703 (2007)
ABSTRACT We examined the physiological and biochemical responses of resistant ('Halt' and 'Prairie Red') and susceptible ('TAM 107') wheat, Triticum aestivum L., to injury by the Russian wheat aphid, Diuraphis noxia (Mordvilko). Photosynthetic capacity was evaluated by measuring assimilation/internal $\mathrm{CO}_{2}\left(\mathrm{~A} / \mathrm{C}_{\mathrm{i}}\right)$ curves, chlorophyll fluorescence, chlorophyll, and nonstructural carbohydrate content. Total protein and peroxidase specific activity also were determined. No significant differences were detected in chlorophyll concentration between aphid-infested and control TAM 107 plants. The aphid-infested resistant cultivars had similar or significantly higher chlorophyll concentrations compared with their respective control plants. Measurements over time showed that infested Halt plants had delays in photosynthetic senescence, Prairie Red plants had photosynthetic rate changes that were similar to control plants, and TAM 107 plants displayed accelerated photosynthetic senescence patterns. The photochemical and nonphotochemical quenching coefficients were significantly higher in infested Halt plants compared with their respective control plants on day 3. Infested TAM 107 plants had significantly higher photochemical quenching compared with control plants at all times evaluated, and they had significantly higher nonphotochemical quenching on day 3 . Throughout the experiment, infested Prairie Red plants exhibited photochemical and nonphotochemical quenching coefficient values that were not significantly different from control plants. Total protein content was not significantly different between aphid-infested and control plants for all cultivars. Differences between physiological responses of infested susceptible and resistant cultivars, particularly temporal changes in photosynthetic activity, imply that resistant Halt and Prairie Red wheat tolerate some impacts of aphid injury on photosynthetic integrity.
\end{abstract}

KEY WORDS plant-insect interaction, gas exchange, photosynthesis, host plant resistance

The Russian wheat aphid, Diuraphis noxia (Mordvilko), has been a significant pest of wheat, Triticum aestivum L., and barley, Hordeum vulgare L., in the United States since its first detection in North America in 1986 (Anderson et al. 2003). Between 1987 and 1992, losses attributed to $D$. noxia feeding were estimated at $\$ 850$ million, with $>100$ million bushels of grain lost in the western United States alone (Quisenberry and Peairs 1998). Losses from $D$. noxia resulted in $\$ 1$ billion by 1993 with cumulative yield losses $>106$ million bushels (Shah et al. 1999).

$D$. noxia usually feeds at the base of the youngest leaves of the plant, which are strong sinks for phloemmobile mineral nutrients, amino compounds, and carbohydrates (Macedo et al. 2003b). By feeding at these sites, $D$. noxia may have the potential to alter carbohydrate-partitioning patterns of wheat and alter sinksource relationships within the plant (Burd et al. 1996). D. noxia also can cause ultrastructural and tis-

\footnotetext{
${ }^{1}$ Department of Entomology, University of Nebraska, Lincoln, NE 68583.

${ }^{2}$ Corresponding author, e-mail: tiffany@unlserve.unl.edu.

${ }^{3}$ USDA-ARS, University of Nebraska, Lincoln, NE 68583.

${ }^{4}$ USDA-ARS, Oklahoma State University, Stillwater, OK 74075.
}

sue-level damage on susceptible hosts, which may affect phloem composition and create a nutritionally enhanced phloem diet (Telang et al. 1999). Feeding by $D$. noxia elicits chlorosis, which takes the form of white or yellow longitudinal bands on leaves (Kazemi et al. 2001) and leaf rolling on cereal plants. A proposed mechanism for the development of chlorosis by piercing-sucking insects (including $D$. noxia) is that chloroplast injury results from the introduction of salivary secretions, some of which may be toxic to the plant (Ni and Quisenberry 2003).

Management of $D$. noxia has largely relied on resistant wheat cultivars (Smith 1999, Webster and Kenkel 1999). Wheat cultivars containing $D$. noxia-resistant genes, which have different levels of antibiosis, tolerance, or both (Randolph et al. 2005a), have been shown to harbor fewer $D$. noxia populations and have higher yields compared with their susceptible wheat counterparts (Randolph et al. 2003, 2005b). Resistant plants also have demonstrated compatibility with other management tactics by exhibiting an absence of leaf rolling when infested with $D$. noxia, which would expose the aphids to chemical and biological management (Hawley et al. 2003). 
Resistant and susceptible plants have not only shown differences with respect to yield and aphid populations in response to $D$. noxia feeding but also with chlorophyll maintenance. Susceptible plants, infested with $D$. noxia, may experience alterations in chlorophyll (Ni et al. 2002) such as chlorosis development, reductions in chlorophyll ( $\mathrm{a}$ and b) and carotenoids, and changes in chlorophyll fluorescence (Burd and Elliott 1996, Rafi et al. 1997). In contrast, resistant plants show minimal or no differences in chlorophyll maintenance in response to $D$. noxia infestation (Burd and Elliott 1996, Heng-Moss et al. 2003).

Another area of research focus has been on understanding how aphid feeding affects plant physiology (e.g., gas-exchange responses and chlorophyll fluorescence). Haile et al. (1999) found that D. noxia-infested resistant and susceptible wheat plants had reduced chlorophyll fluorescence and photosynthetic rates compared with uninfested plants. After aphid removal (7 d), the tolerant cultivar showed a complete recovery of photosynthetic capacity by $7 \mathrm{~d}$, whereas gradual photosynthetic recovery was not observed in the susceptible or antibiotic cultivars. Macedo et al. (2003b) also found that $D$. noxia infestation caused reductions in gas exchange and chlorophyll fluorescence for susceptible wheat, but only under continuous light. Under 72-h continuous dark, aphid infestation did not cause damage symptom formation or reductions in photosynthesis. Development of $D$. noxia feeding damage symptoms (i.e., leaf rolling and chlorotic streaks) on susceptible wheat seedlings may be a lightactivated process, even though the elicitor of the plant damage symptoms is aphid feeding.

Similar reductions in gas exchange and chlorophyll fluorescence also have been found in response to greenbug, Schizaphis graminum (Rondani), feeding. Ryan et al. (1987) showed that a susceptible wheat cultivar had decreased photosynthetic capacity and reduced levels of chlorophyll in response to S. graminum feeding, whereas the resistant cultivar did not show the same reductions. The infested susceptible cultivar also exhibited decreased amounts or activity of rubisco and decreased ribulose 1,5-bisphosphate ( $\mathrm{RuBP}$ ) regeneration.

Previous work has provided insight into differential responses between resistant and susceptible plants; however, a limited number of plant parameters were typically measured. Looking at multiple parameters in combination with a time course would provide a more complete understanding of changes in the physiology of the plant (e.g., gas-exchange responses, nonstructural carbohydrates [NSC]) and offer insight into the short- and long-term changes in cellular processes.

The objectives of this research were to provide a comprehensive overview of several important plant response parameters and document the physiological and biochemical responses of resistant and susceptible wheat to $D$. noxia over a time course. The impact $D$. noxia had on resistant and susceptible plants was specifically measured by examining aphid fecundity, plant height, chlorophyll content, gas-exchange re- sponses, chlorophyll fluorescence kinetics, peroxidase kinetics, protein content, and nonstructural carbohydrate content. Secondarily, observations were made to decipher whether plant parameters measured would be useful in identifying mechanisms of resistance.

\section{Materials and Methods}

\section{Plant Material and Insects}

Seeds of susceptible wheat 'TAM 107' and the resistant wheat 'Halt' and 'Prairie Red' were planted in SC-10 Super Cell Cone-tainers ( 3.8 by $21 \mathrm{~cm}$ ) (Stuewe \& Sons, Inc., Corvallis, OR). The resistant Halt and Prairie Red both carry the Dn4 gene (Quick et al. 1996, Hawley et al. 2003). Three seeds of each cultivar were planted in a Cone-tainer to a depth of $\approx 2 \mathrm{~cm}$ in a mixture of sand-soil-peat-perlite (0.66:0.33:1:1) and placed in Cone-tainer racks. The Cone-tainer racks were then placed over a plastic tray ( 54 by 28 by $6 \mathrm{~cm}$ ) filled with water, to ensure that plants were watered uniformly from the bottom. Plants were grown for $14 \mathrm{~d}$ in a greenhouse under 400-W high intensity lamps with a photoperiod of 16:8 (L:D) h and a temperature of $27 \pm 3^{\circ} \mathrm{C}$. Plants were thinned to one plant per Cone-tainer once seedlings emerged from the soil.

A colony of biotype $1 \mathrm{D}$. noxia was obtained from the USDA-ARS research facility in Stillwater, OK. Aphids were maintained on susceptible TAM 107 wheat, and they were kept in growth chambers (Percival Scientific, Perry, IA) at $21 \pm 1^{\circ} \mathrm{C}, 40-50 \% \mathrm{RH}$, and a photoperiod of 16:8 (L:D) h. The experimental design was a completely randomized design, with a 3 by 2 by 3 factorial treatment design that included three wheat cultivars, two aphid infestation levels ( 0 and $20 \mathrm{D}$. noxia), and three harvest dates $(3,6$, and $9 \mathrm{~d}$ after aphid introduction). The experimental unit was an individual plant, in a Cone-tainer with a Plexiglas cage.

Treatments were a combination of plant cultivars and aphid infestations. For infested treatments, 10 aphids were introduced onto the first and second leaf blade (total of 20 aphids) of each designated infested plant. Tubular, Plexiglas cages $(4 \mathrm{~cm}$ in diameter by 30 $\mathrm{cm}$ in height) were used to confine aphids on the plants with organdy fabric securely fastened by rubber bands to the top of the cages. Uninfested treatment plants were caged just like the infested treatments. After infestation, plants were kept in the greenhouse until the experiment was completed.

Plants were evaluated for leaf chlorosis on each harvest date using a 1-9 scale, where 1 is plants look healthy and 9 is plant death or no recovery possible (Webster et al. 1991). The total number of D. noxia on infested plants was assessed at each harvest date by counting the removed aphids. Plant height (centimeters) was determined at the start of the experiment and also at each harvest interval to calculate the change in growth for the experimental plants. 
Physiological and Biochemical Responses of Wheat to D. noxia

Chlorophyll Concentration. Chlorophyll levels were measured at three locations (near the base of the leaf, the middle, and toward the tip of the leaf) on the first and second leaf blade at each harvest interval by using a chlorophyll meter (model Spad-502, Minolta Camera Co., Osaka, Japan). The arithmetic mean of these measurements was used for all subsequent analyses.

Gas Exchange. Photosynthetic responses of resistant and susceptible wheat were recorded at 3, 6, and $9 \mathrm{~d}$ after aphid introduction by using a portable photosynthesis system (model LI-6400, LI-Cor, Lincoln, $\mathrm{NE}$ ). Although plants were maintained in a greenhouse, all measurements were taken outdoors after plants had acclimatized for $>1 \mathrm{~h}$. Photosynthetic measurements included stomatal conductance (moles of $\mathrm{H}_{2} \mathrm{O}$ per square meter per second) versus intercellular $\mathrm{CO}_{2}$ concentration $\left(\mathrm{C}_{\mathrm{i}}\right)$ (parts per million) and an assimilation rate $(\mathrm{A})$ versus intercellular $\mathrm{CO}_{2}$ concentration $\left(\mathrm{C}_{\mathrm{i}}\right)\left(\mathrm{A} / \mathrm{C}_{\mathrm{i}}\right.$ curve $)$, where rates were measured at 1,400 $\mu$ mol photons $\mathrm{m}^{-2} \mathrm{~s}^{-1}$ light intensity and $\mathrm{CO}_{2}$ concentrations ranging from 50 to $1,000 \mathrm{ppm}$. A/ $\mathrm{C}_{\mathrm{i}}$ response curves and stomatal conductance were determined by the automated programs of the LI- 6400 .

Calculations of the stomatal and nonstomatal components of photosynthesis were made using the methods described by Farquhar and Sharkey (1982). By comparing $\mathrm{A}$ at a $\mathrm{C}_{\mathrm{i}}$ of $400 \mu \mathrm{l}$ liter ${ }^{-1} \mathrm{CO}_{2}$ to $\mathrm{A}$ at the $\mathrm{C}_{\mathrm{i}}$ corresponding to a $\mathrm{C}_{\mathrm{a}}$ (intracellular $\mathrm{CO}_{2}$ ) of $400 \mu \mathrm{l}$ liter ${ }^{-1} \mathrm{CO}_{2}$, the stomatal limitation to photosynthesis can be calculated (Ryan et al. 1987). In equation form, stomatal limitation (SL) can be defined as follows:

$$
\begin{aligned}
\mathrm{SL}=\mathrm{A}\left(\mathrm{C}_{\mathrm{i}}=400 \mu \text { liter }^{-1}\right)- \\
\mathrm{A}\left(\mathrm{C}_{\mathrm{a}}=400 \mu \text { liter }^{-1}\right) / \mathrm{A}\left(\mathrm{C}_{\mathrm{i}}=400 \mu \text { liter }^{-1}\right)
\end{aligned}
$$

The $A$ versus $C_{i}$ response curves also can be used to find the $\mathrm{CO}_{2}$ compensation point (the $\mathrm{C}_{\mathrm{i}}$ value where $\mathrm{A}=0$, given in $\mathrm{Pa}$ ), changes in net $\mathrm{CO}_{2}$ assimilation at saturating $\left(A_{\max }\right)$, and carboxylation efficiency (CE, the slope of the linear portion of the $A$ versus $C_{i}$ response curve). $\mathrm{CE}$ is the region of the $\mathrm{A} / \mathrm{C}_{\mathrm{i}}$ curve where rubisco function is $\mathrm{CO}_{2}$ limited or RuBP saturated and corresponds to the $\mathrm{CE}$ of rubisco (von Caemmerer and Farquhar 1981, Farquhar and Sharkey 1982). Analyses of the $\mathrm{A} / \mathrm{C}_{\mathrm{i}}$ curves also allowed determination of the maximum rate of rubisco-mediated carboxylation $\left(V_{\mathrm{cmax}}\right.$ determined from the linear portion of the curve, micromoles of $\mathrm{CO}_{2}$ per square meter per second) and the maximum potential rate of electron transport contributing to RuBP regeneration ( $J_{\max }$ micromoles of electrons per square meter per second) (Manter and Kerrigan 2004). These values were calculated using the Photosyn Assistant Software (Dundee Scientific, Dundee, Scotland). For each treatment, response curves from leaves of three different plants (replications) were measured and estimated for $\mathrm{SL}, \mathrm{CE}, \mathrm{CO}_{2}$ compensation point, $A_{\max }$, $V_{\text {cmax }}$, and $J_{\text {max }}$.
Chlorophyll Fluorescence. Chlorophyll fluorescence can convey the use of energy absorbed by chlorophyll via photosystem II (PSII) and the degree to which PSII is being damaged by excess light. Chlorophyll fluorescence was measured at each harvest interval using an OS5-FL modulated chlorophyll fluorometer (Opti-Sciences, Tyngsboro, MA). Leaves were dark adapted with clips for at least $20 \mathrm{~min}$ before measurements. Determinations were made of minimum fluorescence for dark-adapted leaves $\left(\mathrm{F}_{\mathrm{o}}\right)$, maximum fluorescence for dark-adapted leaves $\left(\mathrm{F}_{\mathrm{m}}\right)$, fluorescence under steady-state conditions $\left(\mathrm{F}_{\mathrm{s}}\right)$, maximal fluorescence under steady-state conditions $\left(\mathrm{F}_{\mathrm{ms}}\right)$, quantum yield $\left.\left[\mathrm{Y}=\left(\mathrm{F}_{\mathrm{ms}}-\mathrm{F}_{\mathrm{s}}\right) / \mathrm{F}_{\mathrm{ms}}\right)\right]$, photochemical quenching $\left[\mathrm{qP}=\left(\mathrm{F}_{\mathrm{ms}}-\mathrm{F}_{\mathrm{s}}\right) /\left(\mathrm{F}_{\mathrm{ms}}-\mathrm{F}_{\mathrm{o}}\right)\right]$, and nonphotochemical quenching $\left[\mathrm{qN}=\left(\mathrm{F}_{\mathrm{m}}-\right.\right.$ $\left.\mathrm{F}_{\mathrm{ms}}\right) /\left(\mathrm{F}_{\mathrm{m}}-\left[\mathrm{F}_{\mathrm{o}}\right)\right]$ (see OS5-FL Manual for additional details).

Protein and Enzyme Assays. Plant biomass measurements of control and infested plants were recorded on each harvest date. Plant material was ground in liquid nitrogen and prepared for protein analyses by using a modified protocol from Hildebrand et al. (1986) and Heng-Moss et al. (2004). Proteins were extracted with $1.5 \mathrm{ml}$ of HEPES buffer, $\mathrm{pH}$ $7.2,1 \%$ (wt:vol) final concentration of polyvinylpolypyrrolidone, and $1 \mathrm{ml}$ of plant cocktail (Sigma-Aldrich, St. Louis, MO) per $30 \mathrm{~g}$ of plant material by grinding the plant material with a mortar and pestle. This plant mixture was centrifuged at $4^{\circ} \mathrm{C}$ for $10 \mathrm{~min}$, and the supernatant was used for protein assays. A colorimetric protein binding assay (Pierce Chemical, Rockford IL) by using bovine serum albumin as a standard was performed to determine the protein content of the plant extracts (Bradford 1976).

Peroxidase activity was measured by monitoring the increase in absorbance at $470 \mathrm{~nm}$ for $2 \mathrm{~min}$ by using a protocol modified from Hildebrand et al. (1986), Hori et al. (1997), and Heng-Moss et al. (2004). The enzymatic reaction was started by adding $10 \mu \mathrm{l}$ of $30 \%$ hydrogen peroxide to a cuvet containing $300 \mu \mathrm{l}$ of 18 mM guaiacol, $100 \mu \mathrm{l}$ of $200 \mathrm{mM}$ HEPES, pH 7.0, $585 \mu \mathrm{l}$ of distilled water, and $5 \mu$ l of plant extract. The specific activity of peroxidase was determined using the molar absorptivity of guaiacol at $470 \mathrm{~nm}\left(26.6 \times 10^{3} \mathrm{M}^{-1}\right.$ $\left.\mathrm{cm}^{-1}\right)$.

Nonstructural Carbohydrate Determination. Nonstructural carbohydrates were quantified by determining reducing sugar concentrations as glucose equivalents present in the plant material. After storage at $-80^{\circ} \mathrm{C}$, plant material was dried at $70^{\circ} \mathrm{C}$ in a draft oven for $48 \mathrm{~h}$, and then it was mechanically ground. Twenty-five milliliters of $0.02 \mathrm{M}$ benzoic acid was added to a Folin-Wu tube containing a 10-mg sample of the plant material. The tubes were covered loosely with aluminum foil and placed in an autoclave for 20 min on the liquid cycle and slow cooled. The autoclaving step was repeated one additional time to ensure nonstarch oligosaccharides and polysaccharides were hydrolyzed. Approximately $500-\mu l$ aliquots were then diluted to $750 \mu \mathrm{l}$ with $50 \mathrm{mM}$ potassium acetate, $\mathrm{pH} 5$, and $0.02 \mathrm{M}$ benzoic acid. Two-hundred fifty 


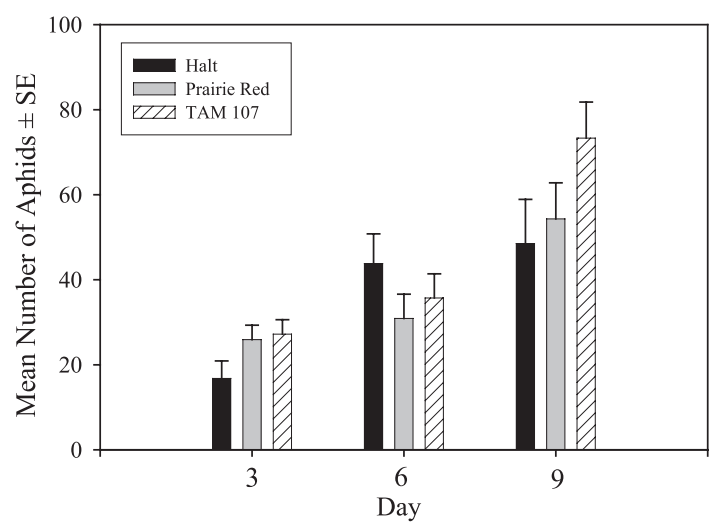

Fig. 1. Mean number of Russian wheat aphids (RWA) produced on each wheat cultivar at 3,6 , and $9 \mathrm{~d}$. No significant differences were detected at $P \leq 0.05$ by LSD.

microliters of an amylase/amyloglucosidase solution was added to the sample, which was then incubated at $42^{\circ} \mathrm{C}$ for $15 \mathrm{~h}$. The solution was then assayed for total extractable carbohydrate according to Nelson-Somogyi copper reducing method (Somogyi 1952). The specific amount of glucose equivalents was quantified by measuring the absorbency of $\mathrm{Cu}_{2} \mathrm{O}$ at $600 \mathrm{~nm}$ by using a spectrophotometer. Known concentrations of glucose were used to generate a standard curve.

Data Analysis. Mixed model analysis (PROC MIXED, SAS Institute 2002) was conducted for each measurement to detect differences in aphid numbers, plant height, protein content, peroxidase specific activity, chlorophyll levels, gas-exchange responses, nonstructural carbohydrate content, and chlorophyll fluorescence measurements. When appropriate, the means were separated according to Fisher least significant difference (LSD) method. Statistical significance was assumed when $P \leq 0.05$.

\section{Results and Discussion}

Physiological Responses of Resistant and Susceptible Wheat to D. noxia

Leaf Chlorosis. Aphid-infested TAM 107 plants showed limited visual damage on day 3 and day 6 (day $3=1.1 \pm 0.13$; day $6=1.1 \pm 0.13$ ). Although not statistically significant, on day 9 aphid-infested TAM 107 plants had increased chlorosis (chlorosis rating = $1.6 \pm 0.13)$ compared with resistant Prairie Red and
Halt plants (chlorosis rating $=1.1 \pm 0.13$ ). Visual evidence of leaf chlorosis was not observed on infested Halt (day $3=1.0$; day $6=1.0$ ) or Prairie Red (day $3=$ 1.0; day $6=1.0$ ) plants throughout the experiment.

Aphid Number. No significant differences were detected in numbers of nymphs among the three wheat cultivars at 3,6 , or $9 \mathrm{~d}$ after aphid introduction $(F=$ 1.8; $\mathrm{df}=2,63 ; P=0.18$ ) (Fig. 1). The greatest number of aphids was recorded on TAM 107 wheat. The resistant Prairie Red and Halt supported similar numbers of aphids throughout the experiment, demonstrating that the two resistant cultivars display tolerance to $D$. noxia. Studies by Randolph et al. (2005a) and Hawley et al. (2003) have previously characterized Prairie Red and Halt as conveying tolerance in the seedling stage and antibiotic properties at later stages of development.

Plant Height. Overall, D. noxia did not have a significant impact on plant growth for any of the cultivars evaluated. All experimental plants grew significantly taller over the course of the experiment $(F=27.2 ; \mathrm{df}=$ $2,121 ; P=0.0001)$. Hawley et al. (2003) also found no significant differences in plant height between $D$. noxia-infested resistant (Halt) and susceptible (TAM 107) plants.

Chlorophyll Concentration. Aphid-infested TAM 107 plants (first leaf blade) had similar chlorophyll concentrations to control plants on all harvest dates (Table 1). There were no significant differences in chlorophyll concentrations between aphid-infested and control resistant plants (Halt and Prairie Red) on day 3 or day 9 . However, on day 6 , there was a significant increase in chlorophyll in aphid-infested resistant plants compared with their respective control plants (Halt: $t=-2.1$, df $=120, P=0.04$; Prairie Red: $t=-2.0$, df $=120, P=0.05)$. For all cultivars and harvest dates evaluated, there were no significant differences in the chlorophyll concentrations of the second leaf blade between infested and control plants (data not shown). Significant differences in the chlorophyll concentration for leaf blade 1 ( $F=23.3$; $\mathrm{df}=$ $2,120 ; P=0.0001)$ and leaf blade $2(F=23.6$;f $=2$, $121 ; P=0.0001)$ were detected among the cultivars. TAM 107 and Prairie Red control plants consistently had higher chlorophyll concentrations compared with Halt control plants.

Previous studies have shown that susceptible cultivars incur chlorophyll loss before resistant plants (Rafi et al. 1997, Burd and Elliott 1996). After an extended period of infestation, resistant plants may

Table 1. Mean \pm SE of chlorophyll loss of leaf blade 1 for resistant Halt and Prairie Red and susceptible TAM 107 wheat at 3 , 6 , and 9 d after exposure to Russian wheat aphid (RWA)

\begin{tabular}{|c|c|c|c|c|c|c|c|c|c|}
\hline \multirow{3}{*}{ Cultivar } & \multicolumn{9}{|c|}{ Mean \pm SE chlorophyll $\left(\mu \mathrm{mol} \mathrm{m}{ }^{-2}\right)$} \\
\hline & \multicolumn{3}{|c|}{ Day 3} & \multicolumn{3}{|c|}{ Day 6} & \multicolumn{3}{|c|}{ Day 9} \\
\hline & Control & RWA & $P$ value $^{a}$ & Control & RWA & $P$ value $^{a}$ & Control & RWA & $P$ value ${ }^{a}$ \\
\hline Halt & $183.9 \pm 30.9$ & $165.9 \pm 25.3$ & 0.65 & $204.9 \pm 27.7$ & $282.7 \pm 25.3$ & 0.04 & $85.3 \pm 30.9$ & $112.7 \pm 25.3$ & 0.49 \\
\hline Prairie Red & $275.3 \pm 20.6$ & $250.8 \pm 20.6$ & 0.40 & $329.1 \pm 20.6$ & $386.3 \pm 20.6$ & 0.05 & $167.5 \pm 20.6$ & $182.2 \pm 20.6$ & 0.62 \\
\hline TAM 107 & $271.6 \pm 20.6$ & $234.8 \pm 20.6$ & 0.21 & $333.2 \pm 21.9$ & $362.1 \pm 20.6$ & 0.33 & $143.8 \pm 20.6$ & $169.4 \pm 20.6$ & 0.38 \\
\hline
\end{tabular}

${ }^{a}$ Significantly different at $P \leq 0.05$ by least significant difference. 
exhibit losses in chlorophyll (Miller et al. 1994), but chlorophyll loss is not as great as in susceptible cultivars (Heng-Moss et al. 2003, Wang et al. 2004). Interestingly, in this study there were no significant differences in chlorophyll concentration between infested and control plants for the susceptible cultivar. Ni et al. (2002) showed that nonchlorotic areas of $D$. noxia-infested susceptible wheat compensated for damaged regions by having increased chlorophyll (a and $\mathrm{b}$ ) and carotenoid concentrations. It is possible, that in our study, nondamaged areas with increased chlorophyll may have masked the reductions in chlorophyll concentration of damaged regions in susceptible plants. This could explain why no significant differences were observed between treatments of the susceptible cultivar.

$\boldsymbol{A}_{\text {max }}$. Over the course of the study, infested TAM 107 and Prairie Red plants had $A_{\max }$ values that were not significantly different from their respective control plants (Figs. 2 and 4). Resistant Halt plants infested with $D$. noxia had significantly higher $A_{\max }$ values on day 3 and 9 compared with control plants (day $3: t=-2.5, \mathrm{df}=19, P=0.02$; day $9: t=-3.5, \mathrm{df}=$ $19, P=0.001$ ) (Fig. 3), suggesting that $D$. noxia infestation in the resistant Halt was not associated with inhibiting the plants' ability to reach maximum photosynthetic capacity.

Stomatal Limitation. There were no significant differences in stomatal limitation across cultivars and treatments throughout the experiment. Similarly, stomatal conductance did not substantially differ among treatments, and stomatal conductance seemed to track with photosynthetic demand (data not shown).

Carboxylation Efficiency. Aphid infestation resulted in significantly lower CE for Prairie Red plants on day $6(t=2.4, \mathrm{df}=23, P=0.02)$ and for TAM 107 plants on day $9(t=2.1, \mathrm{df}=23, P=0.05)$. Throughout the experiment, infested Halt plants showed similar or increased CE values, although not statistically significant, compared with control plants (Figs. 2-4; Table 2 ), suggesting that the CE for this cultivar is not significantly impacted by $D$. noxia.

$\mathrm{CO}_{2}$ Compensation Point. There was a significant day by variety by aphid interaction $(F=3.8 ; \mathrm{df}=4$, $18 ; P=0.02$ ); however, compensation points between aphid treatments of interest were either not significantly different or did not seem to follow an apparent trend (data not shown).

$V_{\text {cmax }}$. Susceptible and resistant plants exhibited trends for $V_{\text {cmax }}$ values that were similar to CE (Table 2 ). At day 6 , susceptible plants infested with $D$. noxia had reduced $V_{\text {cmax }}$ values, and by day 9 infested plants showed significant reductions in $V_{\text {cmax }}$ values compared with control plants $(t=2.7, \mathrm{df}=18, P=0.02)$. These results indicate that the aphids are affecting the plant's ability to reach its maximum rate of rubiscomediated carboxylation. Throughout the experiment, D. noxia-infested Halt plants had $V_{\text {cmax }}$ values that were not significantly different from control plants. Prairie Red plants infested with $D$. noxia had similar values to control plants throughout the experiment, with the exception of day $6(t=2.8, \mathrm{df}=18, P=0.01)$ when values for the infested plants were significantly lower than the control plants.

$J_{\text {max }}$. Susceptible plants infested with D. noxia had declining $J_{\max }$ values over the course of the experiment, with infested plants having significantly lower values compared with control plants on day $6(t=2.1$, $\mathrm{df}=18, P=0.05)$ and day $9(t=3.1, \mathrm{df}=18, P=0.006)$ (Table 2). In contrast, resistant plants infested with $D$. noxia only displayed significant reductions in $J_{\max }$ values on day 6 compared with control plants (Halt: $t=2.3, \mathrm{df}=18, P=0.03$; Prairie Red: $t=3.7, \mathrm{df}=18$, $P=0.002$ ). On days 3 and 9 , infested Halt plants exhibited significantly higher $J_{\max }$ values compared with control plants (Table 2). There were no significant differences between control and infested Prairie Red plants on day 3 or day 9 . Susceptible plants showed accelerated declines in RuBP regeneration in response to aphid feeding, whereas resistant cultivars generally showed comparable or increased RuBP regeneration rates.

Chlorophyll Fluorescence Response. There were no significant differences in the nonvariable $\mathrm{F}_{\mathrm{o}}$ irrespective of aphid treatment for all of the experimental plants (data not shown). Similarities in the $\mathrm{F}_{\mathrm{o}}$ values among aphid treatments strongly suggest that aphid feeding was not associated with photoinhibitory damage in the PSII reaction centers. Aphid infestation was associated with significant differences in $\mathrm{F}_{\mathrm{m}}$ and the total amount of $F_{v}$, but there were no apparent trends between control and infested experimental plants (data not shown).

The photochemical efficiency of PSII $\left(\mathrm{F}_{\mathrm{v}} / \mathrm{F}_{\mathrm{m}}\right)$ ratios provide information on the efficiency of the photochemical system, specifically how much light energy captured is being used by the reaction center and propagated through the photoelectron transport chain. D. noxia did not have a significant impact on $\mathrm{F}_{\mathrm{v}} / \mathrm{F}_{\mathrm{m}}$, indicating that the antennal chlorophyll complexes and electron transfer to the reaction center of PSII was not impacted negatively by aphids. Macedo et al. (2003a) also found that the soybean aphid, Aphis glycines Matsumura, regardless of aphid density, did not alter the photoelectron transport in soybean, Glycine $\max$ (L.) Merr. With sufficient time (i.e., experiments of longer duration), it is likely that photosystem injury can be associated with $D$. noxia infestation, but in this study we observed decreased photosynthetic activity without apparent changes in electron transport.

The yield $(\mathrm{Y})$ of photosynthesis, which gives an indication of the total quantum yield produced by photosynthesis, was significantly impacted by $D$. noxia infestation for resistant plants, but not for susceptible plants (Table 3). Infested Prairie Red plants had significantly higher $\mathrm{Y}$ values compared with control plants on day $6(t=-4.9, \mathrm{df}=462, P=0.0001)$ and day $9(t=-3.3$, df $=462, P=0.001)$. Infested Halt plants had similar Y values to control plants throughout the experiment, with the exception of day 6 when $Y$ values of infested plants were significantly lower (day 6: $t=5.2, \mathrm{df}=462, P=0.0001$ ). $\mathrm{Y}$ is a good indication of the efficiency in light utilization, i.e., how 

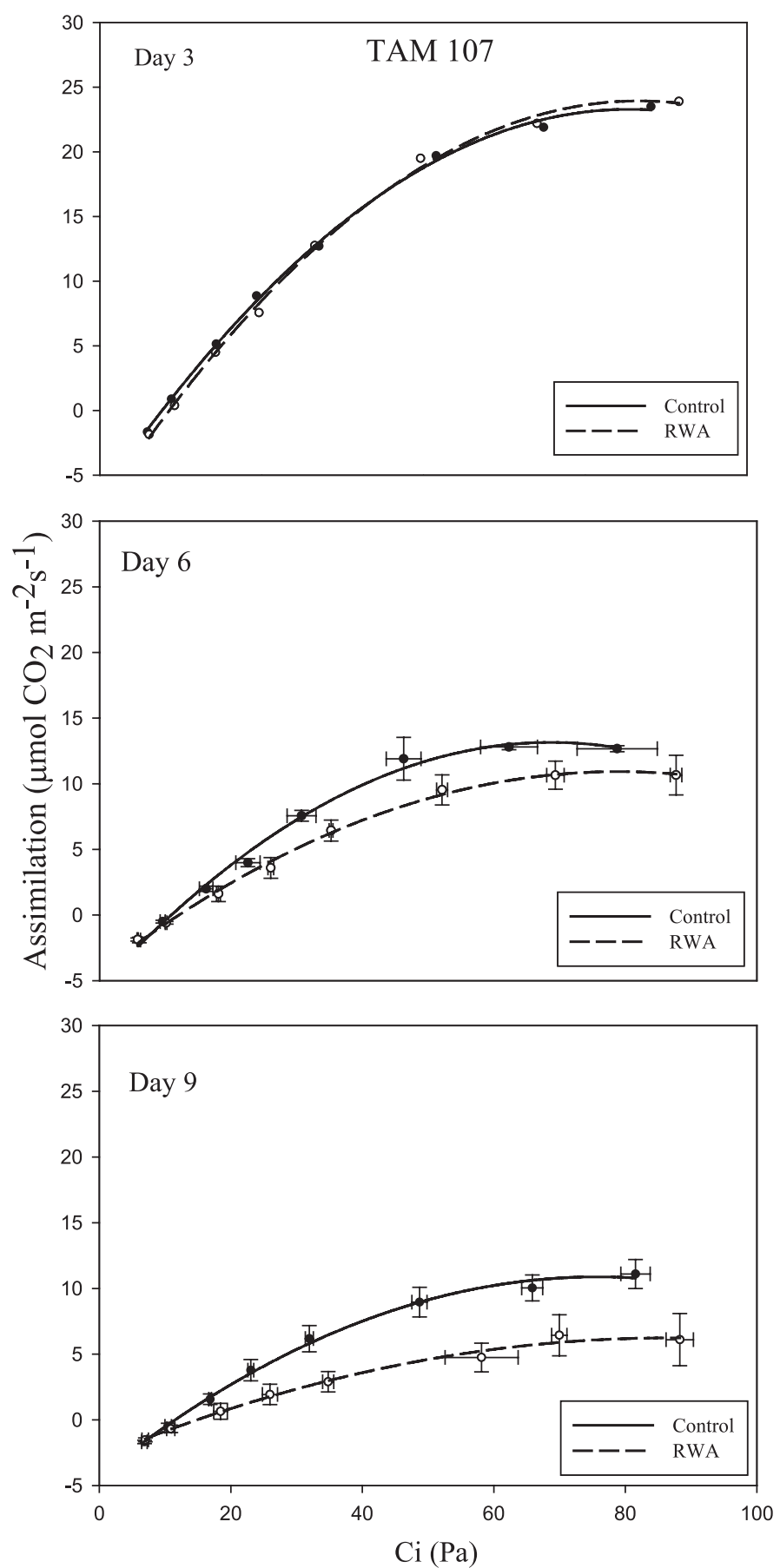

Fig. 2. Assimilation $\left(\mu \mathrm{mol} \mathrm{CO} \mathrm{Cm}^{-2} \mathrm{~s}^{-1}\right.$ ) versus intercellular $\mathrm{CO}_{2}$ concentration $(\mathrm{Ci})$ in pascals $(\mathrm{Pa})$ for susceptible TAM 107 at 3, 6, and $9 \mathrm{~d}$ after Russian wheat aphid (RWA) exposure.

efficiently photons absorbed were converted into chemical products (Malkin and Niyogi 2000). Our results suggest that aphid infestation of resistant plants may play a role in the efficiency of charge separation.

Photochemical fluorescence quenching $(\mathrm{qP})$ was significantly impacted by aphid infestation (Table 3).
Throughout the experiment, infested susceptible plants had significantly higher $\mathrm{qP}$ values compared with control plants (day $3: t=-2.4, \mathrm{df}=471, P=0.02$; day $6: t=-2.0, \mathrm{df}=471, P=0.05$; day $9: t=-5.3, \mathrm{df}=$ $471, P=0.0001)$. Photochemical quenching for infested Halt plants was significantly higher at day $3(t=$ 

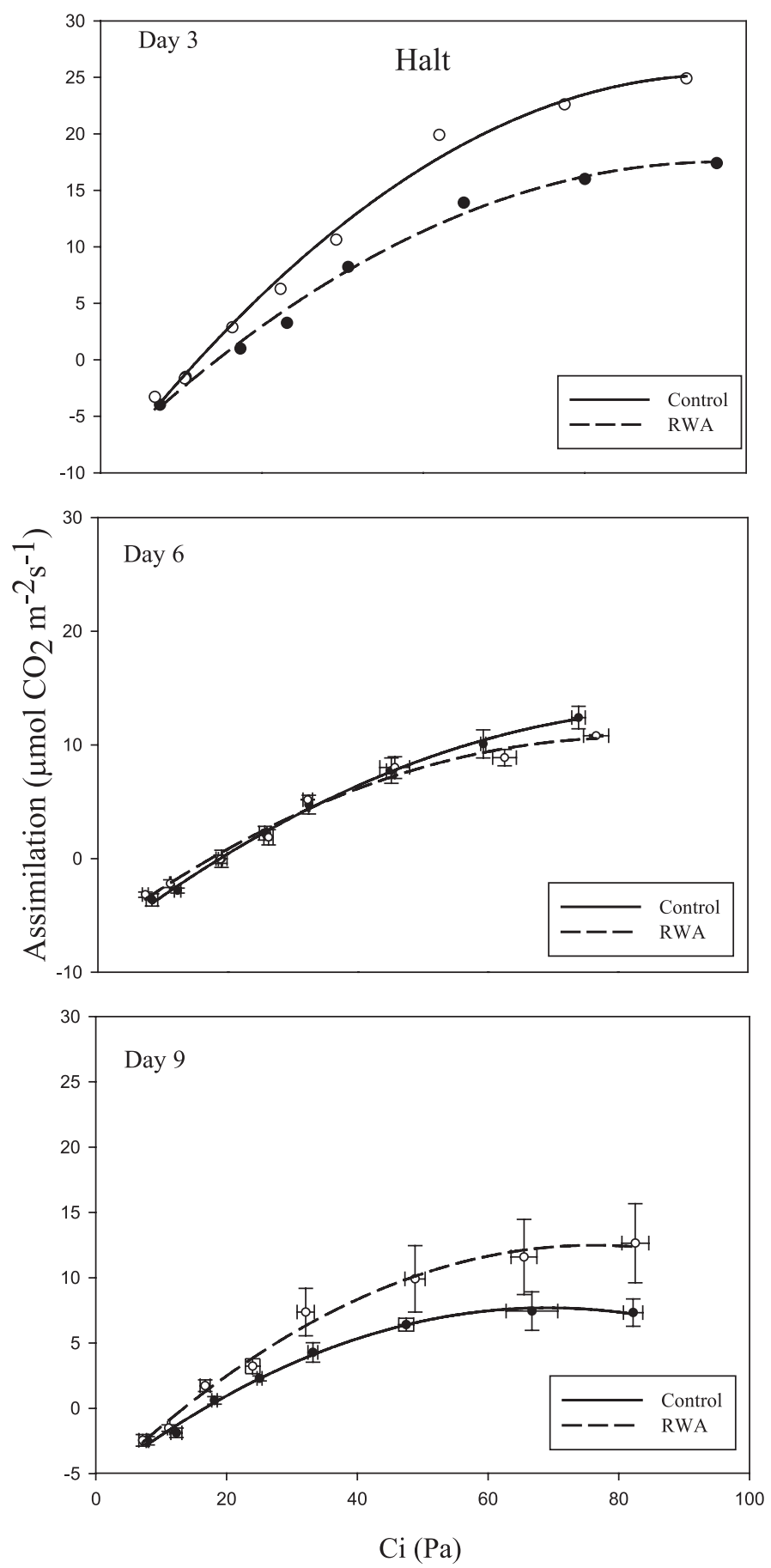

Fig. 3. Assimilation $\left(\mu \mathrm{mol} \mathrm{CO} \mathrm{C}^{-2} \mathrm{~s}^{-1}\right)$ versus intercellular $\mathrm{CO}_{2}$ concentration $(\mathrm{Ci})$ in pascals $(\mathrm{Pa})$ for resistant $\mathrm{Halt}$ at 3,6, and $9 \mathrm{~d}$ after Russian wheat aphid (RWA) exposure.

$-5.2, \mathrm{df}=471, P=0.0001)$ and then remained similar to control plants on days 6 and 9. Infested Prairie Red plants exhibited $\mathrm{qP}$ values that were not significantly different from control and infested plants throughout the course of the experiment.
These data suggest that the resistant plants are able to adjust for changes accompanying aphid feeding that result in minimal disruption of mechanisms that impact qP (Roháček 2002). In contrast, the susceptible genotype seems to be unable to compensate for pho- 

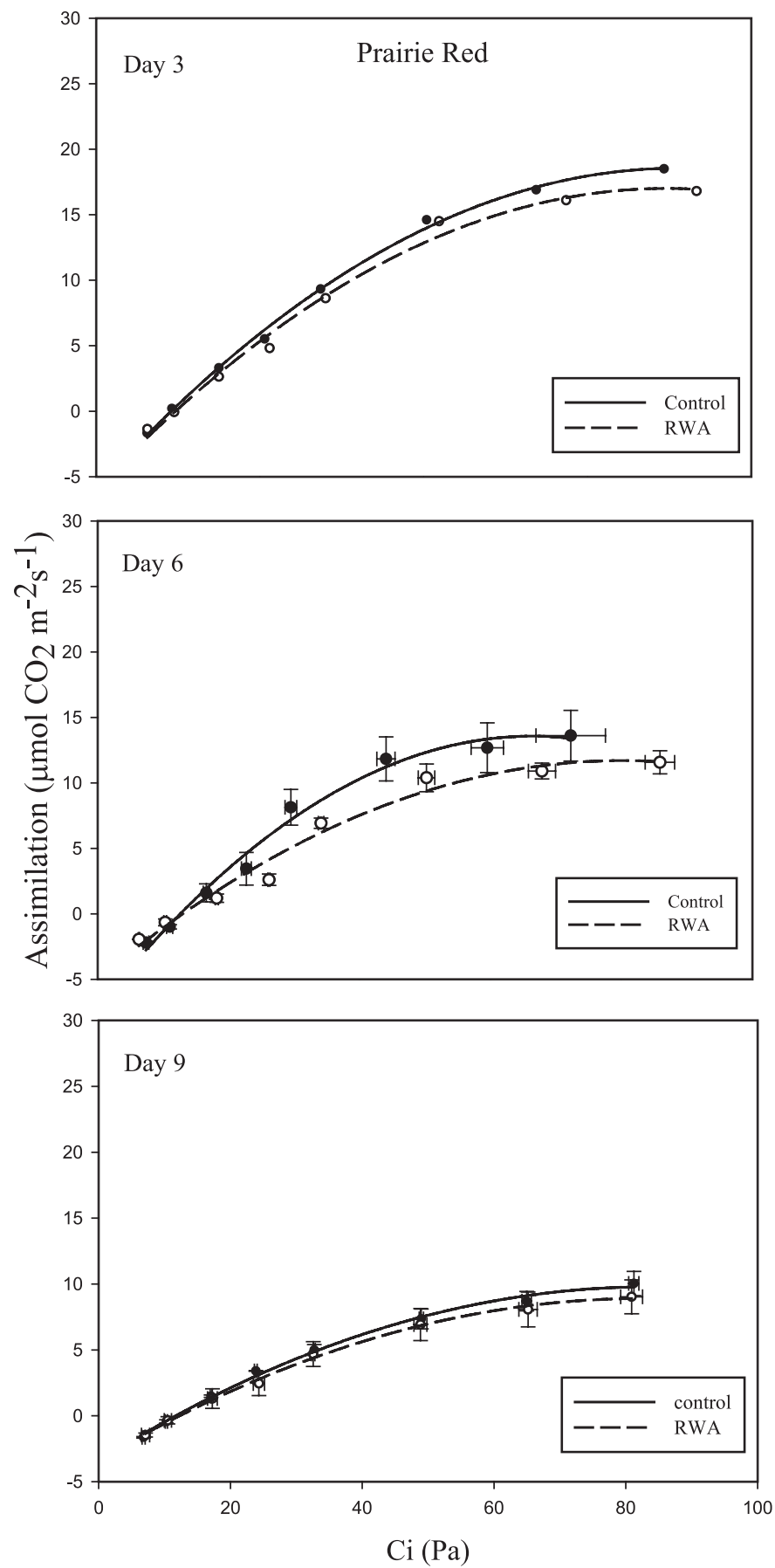

Fig. 4. Assimilation $\left(\mu \mathrm{mol} \mathrm{CO} \mathrm{CO}^{-2} \mathrm{~s}^{-1}\right)$ versus intercellular $\mathrm{CO}_{2}$ concentration $(\mathrm{Ci})$ in pascals $(\mathrm{Pa})$ for resistant Prairie Red at 3, 6, and $9 \mathrm{~d}$ after Russian wheat aphid (RWA) exposure.

tochemical fluorescence quenching under aphid infestation, potentially due to loss of PS-2 centers and/or loss of associated electron-transfer process.

Nonphotochemical fluorescence quenching $(\mathrm{qN})$, a value that relies more on emissions from thylakoid membrane energization (Müller et al. 2001), also was affected by $D$. noxia infestation (Table 3 ). Infested Halt and TAM 107 plants had significantly higher qN values compared with control plants on day 3 (Halt: $t=-5.9, \mathrm{df}=472, P=0.0001 ;$ TAM $107: t=-2.3, \mathrm{df}=$ $472, P=0.02$ ), but subsequently, there were no significant differences between treatments for these two 
Table 2. Mean \pm SE for gas-exchange responses of resistant Halt and Prairie Red and susceptible TAM 107 wheat at 3,6 , and $9 \mathrm{~d}$ after exposure to Russian wheat aphid (RWA)

\begin{tabular}{|c|c|c|c|c|c|c|c|c|c|}
\hline & \multicolumn{9}{|c|}{ Mean \pm SE gas-exchange responses } \\
\hline & \multicolumn{3}{|c|}{$\mathrm{CE}$} & \multicolumn{3}{|c|}{$V_{\mathrm{cmax}}$} & \multicolumn{3}{|c|}{$J_{\max }$} \\
\hline & Control & RWA & $P$ value $^{a}$ & Control & RWA & $P$ value $^{a}$ & Control & RWA & $P$ value \\
\hline \multicolumn{10}{|l|}{ Day 3} \\
\hline Halt & $0.44 \pm 0.07$ & $0.63 \pm 0.07$ & 0.09 & $71.6 \pm 8.1$ & $91.0 \pm 8.1$ & 0.11 & $119 \pm 9.6$ & $167 \pm 9.6$ & 0.002 \\
\hline Prairie Red & $0.50 \pm 0.07$ & $0.42 \pm 0.07$ & 0.46 & $64.8 \pm 8.1$ & $61.7 \pm 8.1$ & 0.80 & $109 \pm 9.6$ & $103 \pm 9.6$ & 0.67 \\
\hline TAM 107 & $0.77 \pm 0.07$ & $0.71 \pm 0.07$ & 0.56 & $75.4 \pm 8.1$ & $87.3 \pm 8.1$ & 0.31 & $134 \pm 9.6$ & $144 \pm 9.6$ & 0.47 \\
\hline \multicolumn{10}{|l|}{ Day 6} \\
\hline Halt & $0.35 \pm 0.04$ & $0.30 \pm 0.05$ & 0.50 & $57.4 \pm 5.7$ & $41.5 \pm 5.7$ & 0.07 & $105 \pm 6.8$ & $83.0 \pm 6.8$ & 0.03 \\
\hline Prairie Red & $0.38 \pm 0.04$ & $0.23 \pm 0.04$ & 0.02 & $62.7 \pm 4.7$ & $43.9 \pm 4.7$ & 0.01 & $103 \pm 6.8$ & $67.5 \pm 6.8$ & 0.002 \\
\hline TAM 107 & $0.36 \pm 0.04$ & $0.27 \pm 0.04$ & 0.16 & $54.7 \pm 4.7$ & $42.8 \pm 5.7$ & 0.13 & $88 \pm 5.5$ & $71.7 \pm 5.5$ & 0.05 \\
\hline \multicolumn{10}{|l|}{ Day 9} \\
\hline Halt & $0.29 \pm 0.04$ & $0.36 \pm 0.04$ & 0.22 & $32.1 \pm 5.7$ & $44.3 \pm 5.7$ & 0.15 & $65.7 \pm 6.8$ & $97.1 \pm 6.8$ & 0.04 \\
\hline Prairie Red & $0.29 \pm 0.04$ & $0.23 \pm 0.04$ & 0.30 & $23.2 \pm 4.7$ & $21.1 \pm 4.7$ & 0.76 & $59.6 \pm 5.5$ & $54.1 \pm 5.5$ & 0.49 \\
\hline TAM 107 & $0.31 \pm 0.04$ & $0.18 \pm 0.04$ & 0.05 & $35.2 \pm 5.7$ & $15.3 \pm 4.7$ & 0.02 & $66.1 \pm 5.5$ & $41.5 \pm 5.5$ & 0.006 \\
\hline
\end{tabular}

${ }^{a}$ Significantly different at $P \leq 0.05$ by least significant difference.

cultivars on days 6 and 9. Infested Prairie Red plants exhibited qN values that were not significantly different from control and infested plants throughout the course of the experiment. These data suggest that qN may not be as important a factor in these genotypes and that all three plants possess adequate mechanisms to correct for emissions arising from thylakoid membrane energization.

Significant changes in the quenching coefficients, especially in the susceptible cultivar, suggest that aphid feeding may influence the photoprotective xanthophyll cycle by altering the $\mathrm{pH}$ gradient across the thylakoid membrane (Macedo et al. 2003a). Changes in trans-thylakoid $\mathrm{pH}$ might compromise synthesis of zeaxathin by the xanthophylls deepoxidase enzyme, which could lead to increased formation of triplet state chlorophyll and singlet state oxygen, thereby decreasing the efficiency of photosynthesis (Malkin and Niyogi 2000). Our findings, which are similar to Macedo et al. (2003a), indicate that chlorophyll may not be directly impacted by aphid injury but rather by biochemical mechanisms involved with quenching may be more immediately impacted by aphid feeding.
Protein Content. Total protein content was not significantly different between aphid-infested and control plants for the three cultivars evaluated (Table 4). Over the course of the experiment, there was a significant decline in total protein for all three cultivars $(F=6.3 ; \mathrm{df}=2,54 ; P=0.004)$. Changes in protein followed a normal senescence pattern among all wheat cultivars (Dangl et al. 2000).

Peroxidase Specific Activity. Peroxidase specific activity was not significantly different between aphidinfested and control plants for the three cultivars evaluated $(F=0.5 ; \mathrm{df}=4,53 ; P=0.73)$. In general, aphid feeding resulted in the up-regulation of peroxidase activity in resistant cultivars, but not in susceptible plants (Table 4). However, the timing of up-regulation differed between resistant cultivars with the greatest increase for Prairie Red at day 3 and day 6 for Halt.

Previous studies by van der Westhuizen et al. (1998) also have documented increased peroxidase activity in Russian wheat aphid-resistant wheat. They investigated the intercellular peroxidase and chitinase activities of three wheat cultivars ('Tugela DN', 'Molopo $\mathrm{DN}^{\prime}$, and 'Betta $\mathrm{DN}^{\prime}$ ) resistant to the Russian wheat

Table 3. Mean \pm SE of chlorophyll fluorescence responses for resistant Halt and Prairie Red and susceptible TAM 107 wheat at 3 , 6, and $9 \mathrm{~d}$ after Russian wheat aphid (RWA) exposure

\begin{tabular}{|c|c|c|c|c|c|c|c|c|c|}
\hline & \multicolumn{9}{|c|}{ Mean \pm SE chlorophyll fluorescence responses } \\
\hline & \multicolumn{3}{|c|}{$\mathrm{Y}$} & \multicolumn{3}{|c|}{$\mathrm{qP}$} & \multicolumn{3}{|c|}{$\mathrm{qN}$} \\
\hline & Control & RWA & $P$ value ${ }^{a}$ & Control & RWA & $P$ value ${ }^{a}$ & Control & RWA & $P$ value ${ }^{a}$ \\
\hline \multicolumn{10}{|l|}{ Day 3} \\
\hline Halt & $0.09 \pm 0.005$ & $0.11 \pm 0.005$ & 0.07 & $0.58 \pm 0.3$ & $2.47 \pm 0.3$ & 0.0001 & $0.31 \pm 0.06$ & $0.62 \pm 0.06$ & 0.0001 \\
\hline Prairie Red & $0.09 \pm 0.005$ & $0.11 \pm 0.008$ & 0.17 & $1.22 \pm 0.3$ & $1.53 \pm 0.3$ & 0.45 & $0.24 \pm 0.06$ & $0.35 \pm 0.07$ & 0.06 \\
\hline TAM 107 & $0.08 \pm 0.005$ & $0.08 \pm 0.005$ & 0.63 & $1.23 \pm 0.3$ & $2.08 \pm 1.3$ & 0.02 & $0.26 \pm 0.06$ & $0.37 \pm 0.06$ & 0.02 \\
\hline \multicolumn{10}{|l|}{ Day 6} \\
\hline Halt & $0.15 \pm 0.009$ & $0.09 \pm 0.007$ & 0.0001 & $0.59 \pm 0.10$ & $0.70 \pm 0.08$ & 0.79 & $0.81 \pm 0.02$ & $0.83 \pm 0.02$ & 0.73 \\
\hline Prairie Red & $0.09 \pm 0.007$ & $0.13 \pm 0.007$ & 0.0001 & $0.35 \pm 0.08$ & $0.66 \pm 0.08$ & 0.38 & $0.81 \pm 0.02$ & $0.82 \pm 0.02$ & 0.91 \\
\hline TAM 107 & $0.13 \pm 0.007$ & $0.13 \pm 0.007$ & 0.22 & $0.42 \pm 0.08$ & $1.12 \pm 0.08$ & 0.05 & $0.78 \pm 0.02$ & $0.85 \pm 0.02$ & 0.18 \\
\hline \multicolumn{10}{|l|}{ Day 9} \\
\hline Halt & $0.11 \pm 0.007$ & $0.10 \pm 0.008$ & 0.16 & $0.79 \pm 0.3$ & $0.74 \pm 0.4$ & 0.89 & $0.84 \pm 0.01$ & $0.83 \pm 0.02$ & 0.83 \\
\hline Prairie Red & $0.10 \pm 0.007$ & $0.14 \pm 0.008$ & 0.001 & $0.49 \pm 0.3$ & $0.54 \pm 0.4$ & 0.89 & $0.81 \pm 0.01$ & $0.74 \pm 0.02$ & 0.21 \\
\hline TAM 107 & $0.09 \pm 0.007$ & $0.09 \pm 0.008$ & 0.89 & $0.39 \pm 0.3$ & $2.5 \pm 0.4$ & 0.0001 & $0.81 \pm 0.01$ & $0.89 \pm 0.02$ & 0.20 \\
\hline
\end{tabular}

${ }^{a}$ Significantly different at $P \leq 0.05$ by least significant difference. 
Table 4. Mean $\pm \mathrm{SE}$ protein concentration and peroxidase specific activity of resistant Halt and Prairie Red and susceptible TAM 107 wheat at 3, 6, and $9 \mathrm{~d}$ after Russian wheat aphid (RWA) exposure

\begin{tabular}{|c|c|c|c|c|c|c|}
\hline & \multicolumn{3}{|c|}{ Protein (mg/g) } & \multicolumn{3}{|c|}{$\begin{array}{l}\text { Peroxidase activity } \\
(\mu \mathrm{mol} / \mathrm{min} / \mathrm{mg})\end{array}$} \\
\hline & Control & RWA & $P$ value $^{a}$ & Control & RWA & $P$ value ${ }^{a}$ \\
\hline \multicolumn{7}{|l|}{ Day 3} \\
\hline Halt & 14.6 & 12.5 & 0.48 & 0.60 & 0.59 & 0.97 \\
\hline Prairie Red & 10.2 & 12.5 & 0.45 & 0.63 & 0.97 & 0.11 \\
\hline TAM 107 & 14.0 & 15.9 & 0.52 & 0.76 & 0.77 & 0.97 \\
\hline \multicolumn{7}{|l|}{ Day 6} \\
\hline Halt & 10.5 & 8.2 & 0.45 & 0.41 & 0.75 & 0.09 \\
\hline Prairie Red & 8.2 & 8.8 & 0.82 & 0.41 & 0.49 & 0.70 \\
\hline TAM 107 & 9.6 & 8.9 & 0.83 & 0.43 & 0.56 & 0.54 \\
\hline \multicolumn{7}{|l|}{ Day 9} \\
\hline Halt & 11.8 & 10.2 & 0.61 & 0.50 & 0.63 & 0.49 \\
\hline Prairie Red & 10.4 & 8.0 & 0.42 & 0.36 & 0.50 & 0.50 \\
\hline TAM 107 & 11.3 & 10.8 & 0.86 & 0.53 & 0.56 & 0.86 \\
\hline
\end{tabular}

SE: protein $=2.1$; peroxidase activity $=0.1$

${ }^{a}$ Significantly different at $P \leq 0.05$ by least significant difference.

aphid and three corresponding near-isogenic susceptible cultivars ('Tugela', 'Molopo', and 'Betta'). In all cultivars, the peroxidase activity in control susceptible and resistant plants was very low and remained constant throughout the experiment. Peroxidase activity was shown to increase in response to aphid feeding in all three resistant plants, whereas susceptible plants infested with aphids showed no significant increase (Tugela) in peroxidase activity or a delayed increase at a very late infestation stage (Molopo and Betta).

The accumulation of peroxides, a process that takes place during plant senescence patterns, is normally a highly regulated and subtle signaling mechanism in viable cells. When a plant is stressed by injury, such as aphid feeding, alternative senescence patterns or plant cell death pathways may be initiated (Leitner et al. 2005) that cause increased production of oxygen radicals in plants. Susceptible plants may not be able to combat the unregulated production of oxygen radicals. The accumulation of these unregulated oxygen radicals can lead to altered senescence patterns (Dangl et al. 2000).

Nonstructural Carbohydrate Concentration. The effect of $D$. noxia feeding on NSC profiles also was investigated (Table 5). Although there were significant differences, no consistent trend was observed. The only significant interaction of interest between treatments for a wheat cultivar was observed for Halt plants on day $9(t=-3.1$, df $=25, P=0.005)$, where infested plants had significantly higher NSC levels from control plants.

The effect of $D$. noxia on soluble carbohydrates (expressed as percentage dry weight) did not seem to deplete or cause altered partitioning patterns for Prairie Red and Halt. TAM 107 plants infested with $D$. noxia consistently had similar or reduced NSC levels compared with control plants, suggesting that alterations in photosynthetic rates may have been correlated with declining NSC levels. Nonstructural carbohydrate levels can be an informative plant parameter, but in this case, may not be precise enough to detect
Table 5. Mean \pm SE NSC concentrations of resistant Halt and Prairie Red and susceptible TAM 107 wheat at 3, 6, and $9 \mathrm{~d}$ after Russian wheat aphid (RWA) exposure

\begin{tabular}{lccc}
\hline \hline & \multicolumn{3}{c}{ NSC carbohydrates } \\
& Control & RWA & $P$ value $^{a}$ \\
\cline { 2 - 4 } & & & \\
\hline Day 3 & $51.8 \pm 14.0$ & $45.5 \pm 11.4$ & 0.73 \\
Halt & $50.8 \pm 14.0$ & $52.6 \pm 14.0$ & 0.93 \\
Prairie Red & $43.0 \pm 11.4$ & $40.2 \pm 11.4$ & 0.86 \\
TAM 107 & & & \\
Day 6 & $151.8 \pm 14.0$ & $173.0 \pm 14.0$ & 0.29 \\
Halt & $210.7 \pm 11.4$ & $237.5 \pm 11.4$ & 0.11 \\
Prairie Red & $183.0 \pm 14.0$ & $173.8 \pm 11.4$ & 0.62 \\
TAM 107 & $70.8 \pm 14.0$ & $131.2 \pm 14.0$ & 0.005 \\
Day 9 & $143.0 \pm 14.0$ & $157.0 \pm 14.0$ & 0.49 \\
Halt & $187.8 \pm 14.0$ & $166.2 \pm 11.4$ & 0.24 \\
Prairie Red & & & \\
TAM 107 & & & \\
\hline
\end{tabular}

${ }^{a}$ Significantly different at $P \leq 0.05$ by least significant difference.

differences in partitioning patterns (alterations toward storage forms versus translocated forms of carbohydrate) resulting from aphid feeding. In the future, different forms of carbohydrates (starch, sucrose, hexose, and fructose) should be measured in relation to NSC.

\section{Integrated Responses}

Overall, there was a decline in photosynthetic capacity for all wheat plants over the course of the experiment, but aphid infestation seemed to have a different effect on resistant and susceptible cultivars. Generally, as plants senesce there are declines in photosynthetic capacity as well as alterations in plant metabolism. The observed decline in photosynthetic capacity may have involved the cytochrome b6f electron transport complex, PSII, the carbon-fixing reaction catalyzed by rubisco, or a combination (Lambers et al. 1998). Results from this study suggest that resistant plants subjected to $D$. noxia feeding maintained or compensated for aphid injury by altering their senescence pathways, whereas susceptible plants seemed to have an accelerated senescence pattern.

Infested Halt plants exhibited delayed senescence patterns by maintaining a steady photosynthetic activity over time despite aphid feeding, whereas the control plants exhibited normal declines in photosynthetic capacity as the plant aged. However, infested and control Prairie Red plants had similar photosynthetic rates throughout the experiment. Based upon these results, it is likely that infested Prairie Red plants exhibited photosynthetic compensation. Even though Halt and Prairie Red both possess the Dn4 gene (for D. noxia resistance) (Randolph et al. 2005a), the mechanisms of resistance seem to be different with respect to gas-exchange responses.

Gas-exchange processes rapidly respond to external factors and provide an immediate indication of plant stress (Peterson and Higley 1993) as well as a common biological basis for comparison of herbivore impact on different plants (Welter 1989). In this study, we ob- 
served asymptomatic plants to have reduced gas-exchange responses despite the lack of visual chlorosis or reductions in chlorophyll content. Based upon these observations, it is evident that gas-exchange responses are a more sensitive physiological parameter than chlorophyll measurements. Moreover, it seems likely that altered chlorophyll levels may be a secondary effect and not the primary trigger of declined host plant function (Macedo et al. 2003a).

Previous studies on how aphids alter plant gas-exchange processes have indicated that photosynthetic inhibitions occur before $\mathrm{CO}_{2}$ assimilation with rubisco (Ryan et al. 1987, Haile et al. 1999). In general, we found that TAM 107 (susceptible cultivar) plants infested with $D$. noxia had decreased rubsico activity and $\mathrm{RuBP}$ regeneration rates compared with control plants. These results suggest that as the rate of incorporation and/or export of photosynthetic products declines, photosynthesis becomes restricted by "feedback inhibition" (Lambers et al. 1998) and results in alterations of source-sink feedback signals (Peterson and Higley 1993). Resistant plants infested with Russian wheat aphids had comparable or increased RuBP rates, which suggest faster regeneration of RuBP.

This study provides evidence to support our working hypothesis that end-product inhibition plays an important role in reduced photosynthetic rates of susceptible plants (Macedo 2003). Resistant plants seem to counteract deleterious effects of aphid herbivory on leaves through up-regulation of detoxification mechanisms and faster regeneration of photosynthetic active centers and RuBP. In contrast, our data suggest that leaves of susceptible plants are unable to sustain these processes and become senescent. Overall, it would seem that the initial response in all wheat plants to aphid feeding is similar, but the extent of recovery (level of resistance) is determined by several complimentary cellular pathways (i.e., elicitor pathways and cellular metabolism). These pathways apparently allow a source leaf on a resistant plant to overcome the negative effects of aphid feeding and maintain adequate rates of photosynthesis that supports continued plant growth.

\section{Acknowledgments}

We thank Drs. G. Hein and F. Peairs for plant material. We gratefully acknowledge Z B Mayo for reviewing this manuscript. This research was supported in part by the University of Nebraska Agriculture Experiment Station Project 17-078 and 17-080. This is paper no. 15227 of the journal series of the Agricultural Research Division, University of NebraskaLincoln.

\section{References Cited}

Anderson, G. R., D. Papa, J. Peng, M. Tahir, and N. L. Lapitan. 2003. Genetic mapping of $\mathrm{Dn} 7$, a rye gene conferring resistance to the Russian wheat aphid in wheat. Theor. Appl. Genet. 107: 1297-303.

Bradford, M. M. 1976. A rapid and sensitive method for the quantification of microgram quantities of protein utilizing the principle of protein-dye binding. Anal. Biochem. 72: 248-254.

Burd, J. D., and N. C. Elliott. 1996. Changes in chlorophyll a fluorescence induction kinetics in cereals infested with Russian wheat aphid. J. Econ. Entomol. 89: 1332-1337.

Burd, J. D., J. A. Webster, G. J. Puterka, R. P. Hoxie, and S. G. Wellso. 1996. Effect of Russian wheat aphid on constituent and nonconstituent carbohydrate content in wheat seedlings. Southwest. Entomol. 21: 167-172.

Dangl, J. L., R. A. Dietrich, and H. Thomas. 2000. Senescence and programmed cell death, chapter 20. In B. Buchanan, W. Gruissem, and R. Jones [eds.], Biochemistry and molecular biology of plants. American Society of Plant Physiology, Rockville, MD.

Farquhar, G. D., and T. D. Sharkey. 1982. Stomatal conductance and photosynthesis. Annu. Rev. Plant Physiol. 33: 317-345.

Haile, F. J., L. G. Higley, X. Ni, and S. S. Quisenberry. 1999. Physiological and growth tolerance in wheat to Russian wheat aphid (Homoptera: Aphididae) injury. Environ. Entomol. 28: 787-794.

Hawley, C. J., F. B. Peairs, and T. L. Randolph. 2003. Categories of resistance at different growth stages in 'Halt', a winter wheat resistant to the Russian wheat aphid (Homoptera: Aphididae). J. Econ. Entomol. 96: 214-219.

Heng-Moss, T. M., X. Ni, T. Macedo, J. P. Markwell, F. P. Baxendale, S. S. Quisenberry, and V. Tolmay. 2003. Comparison of chlorophyll and carotenoid concentrations among Russian wheat aphid (Homoptera: Aphididae)-infested wheat isolines. J. Econ. Entomol. 96: 475481.

Heng-Moss, T., G. Sarath, F. Baxendale, D. Novak, S. Bose, X. Ni, and S. Quisenberry. 2004. Characterization of oxidative enzyme changes in buffalograsses challenged by Blissus occiduus. J. Econ. Entomol. 97: 1086-1095.

Hildebrand, D. F., J. G. Rodriguez, G. C. Brown, K. T. Luu, and C. S. Volden. 1986. Peroxidative responses of leaves in two soybean genotypes injured by twospotted spider mites (Acari: Tetranychidae). J. Econ. Entomol. 79: 14591465.

Hori, K., A. Wada, and T. Shibuta. 1997. Changes in phenoloxidase activities of the galls on leaves of Ulmus davidana formed by Tetraneura fusiformis (Homoptera: Eriosomatidae). Appl. Entomol. Zool. 32: 365-371.

Kazemi, M. H., P. Talebi-Chaichi, M. R. Shakiba, and M. M. Jafarloo. 2001. Biological responses of Russian wheat aphid, Diuraphis noxia (Mordvilko) (Homoptera: Aphididae) to different wheat varieties. J. Agric. Sci. Technol. 3: $249-255$.

Lambers, H., F. Stuart Chapin, III, and T. L. Pons. 1998. Plant physiological ecology. Springer, New York.

Leitner, M., W. Boland, and A. Mithöfer. 2005. Direct and indirect defenses induced by piercing-sucking and chewing herbivores in Medicago truncatula. New Phytol. 167: 597-606.

Macedo, T. 2003. Physiological responses of plants to piercing-sucking arthropods. Ph.D. dissertation. University of Nebraska-Lincoln, Lincoln, NE.

Macedo, T. B., C. S. Bastos, L. G. Higley, K. R. Ostlie, and S. Madhavan. 2003a. Photosynthetic responses of soybean to soybean aphid (Homoptera: Aphididae) injury. J. Econ. Entomol. 96: 188-193.

Macedo, T. B., L. G. Higley, X. Ni, and S. S. Quisenberry. 2003b. Light activation of Russian wheat aphid-elicited physiological responses in susceptible wheat. J. Econ. Entomol. 96: 194-201.

Malkin, R., and K. Niyogi. 2000. Photosynthesis. In B. Buchanan, W. Gruissem, and R. Jones. [eds.], Biochem- 
istry and molecular biology of plants. American Society of Plant Physiology, Rockville, MD.

Manter, D. K., and J. Kerrigan. 2004. A/ $C_{i}$ analysis across a range of woody plant species: influence of regression analysis parameters and mesophyll conductance. J. Exp. Bot. 55: 2581-2588.

Miller, H., D. R. Porter, J. D. Burd, D. W. Mornhinweg, and R. L. Burton. 1994. Physiological effects of Russian wheat aphid on resistant and susceptible barley. J. Econ. Entomol. 87: 493-499.

Müller, P., X. Li, and K. K. Niyogi. 2001. Non-photochemical quenching: a response to excess light energy. Plant Physiol. 125: 1558-1566.

Ni, X., and S. Quisenberry. 2003. Possible roles of esterase glutathione S-transferase, and superoxide dismutase activities in understanding aphid-cereal interactions. Entomol. Exp. Appl. 108: 187-195.

Ni, X., S. S. Quisenberry, T. Heng-Moss, J. Markwell, L. Higley, F. Baxendale, G. Sarath, and R. Klucas. 2002. Dynamic change in photosynthetic pigments and chlorophyll degradation elicited by cereal aphid feeding. Entomol. Exp. Appl. 105: 43-53.

Peterson, R. K., and L. G. Higley. 1993. Arthropod injury and plant gas exchange: current understandings and approaches for synthesis. Trends Agric. Sci. 1: 93-100.

Quick, J. S., G. E. Ellis, R. M. Normann, J. A. Stromberger, J. F. Shanahan, F. B. Peairs, J. B. Rudolph, and K. Lorenz. 1996. Registration of 'Halt' wheat. Crop Sci. 36: 210.

Quisenberry, S. S., and F. B. Peairs. 1998. Response model for an introduced pest: the Russian wheat aphid. Entomological Society of America, Lanham, MD.

Rafi, M. M., R. S. Zemetra, and S. S. Quisenberry. 1997. Feeding damage of Russian wheat aphid on resistant and susceptible wheat genotypes. Cereal Res. Commun. 25: 63-68.

Randolph, T. L., F. B. Peairs, M. K. Kroening, J. S. Armstrong, R. W. Hammon, C. B. Walker, and J. S. Quick. 2003. Plant damage and yield response to the Russian wheat aphid (Homoptera: Aphididae) on susceptible and resistant winter wheats in Colorado. J. Econ. Entomol. 96: 352-360.

Randolph, T. L., F. B. Peairs, M. Koch, C. B. Walker, J. R. Stubbs, J. S. Quick, and S. D. Haley. 2005a. Yield response and categories of resistance to Russian wheat aphid in four Dn4 hard red winter wheat cultivars. J. Econ. Entomol. 98: 588-594.

Randolph, T. L., F. B. Peairs, M. Koch, C. B. Walker, and J. S. Quick. 2005b. Influence of three resistance sources in winter wheat derived from TAM 107 on yield response to Russian wheat aphid. J. Econ. Entomol. 98: 389-394.
Roháček, K. 2002. Chlorophyll fluorescence parameters: the definitions, photosynthetic meaning and mutual relationships. Photosynthetica 40: 13-29.

Ryan, J. D., R. C. Johnson, R. D. Eikenbary, and K. W. Dorschner. 1987. Drought/greenbug interactions: photosynthesis of greenbug resistant and susceptible wheat. Crop Sci. 27: 283-288.

SAS Institute. 2002. PROC user's manual, version 9.1. SAS Institute, Cary, NC.

Shah, P. A., J. A. Pickett, and J. D. Vandenberg. 1999. Responses of Russian wheat aphid (Homoptera: Aphididae) to aphid alarm pheromone. Environ. Entomol. 28: 983985.

Smith, C. M. 1999. Plant resistance to insects, pp. 171-205. In J. Rechcigl and N. Rechcigl [eds.], Biological and biotechnological control of insects. Lewis, Boca Raton, FL.

Somogyi, M. 1952. Notes on sugar determination. J. Biol. Chem. 195: 19-23.

Telang, A., J. Sandström, E. Dyreson, and N. A. Moran. 1999. Feeding damage by Diuraphis noxia results in a nutritionally enhanced phloem diet. Entomol. Exp. Appl. 91: 403-412.

van der Westhuizen, A. J., X. M. Qian, and A. M. Botha. 1998. Differential induction of apoplastic peroxidase and chitinase activities in susceptible and resistant wheat cultivars by Russian wheat aphid infestation. Plant Cell Rep. 18: 132-137.

von Caemmerer, S., and G. D. Farquhar. 1981. Some relationships between the biochemistry of photosynthesis and the gas exchange of leaves. Planta 153: 376-387.

Wang, T., S. S. Quisenberry, X. Ni, and V. Tolmay. 2004. Aphid (Hemiptera: Aphididae) resistance in wheat nearisogenic lines. J. Econ. Entomol. 97: 646-653.

Webster J. A., and P. Kenkel. 1999. Benefits of managing small-grain pests with plant resistance, pp. 87-114. In B. R. Wiseman and J. A. Webster [eds.], Proceedings, Thomas Say Publications in Entomology. Entomological Society of America, Lanham, MD.

Webster, J. A., C. A. Baker, and D. R. Porter. 1991. Detection and mechanisms of Russian wheat aphid (Homoptera: Aphididae) resistance in barley. J. Econ. Entomol. 84: 669-673.

Welter, S. C. 1989. Arthropod impact on plant gas exchange. In E. A. Bernays [ed.], Insect-plant interactions, vol. 1. CRC, Boca Raton, FL.

Received 19 June 2006; accepted 25 June 2007. 